\title{
Electrical and Magnetic Properties of Polymer Electrolyte (PVA:LiOH) Containing In Situ Dispersed $\mathrm{Fe}_{3} \mathrm{O}_{4}$ Nanoparticles
}

\author{
M. P. Aji, ${ }^{1}$ Rahmawati, ${ }^{1}$ Masturi, ${ }^{1}$ S. Bijaksana, ${ }^{2}$ Khairurrijal, $^{1}$ and M. Abdullah ${ }^{1}$ \\ ${ }^{1}$ Department of Physics, Bandung Institute of Technology (ITB), Bandung 40132, Indonesia \\ ${ }^{2}$ Department of Petroleum Engineering, Bandung Institute of Technology (ITB), Bandung 40132, Indonesia
}

Correspondence should be addressed to M. Abdullah, mikrajuddin@gmail.com

Received 24 October 2011; Accepted 14 November 2011

Academic Editors: N. Guarrotxena and R. A. Varin

Copyright ( $) 2012$ M. P. Aji et al. This is an open access article distributed under the Creative Commons Attribution License, which permits unrestricted use, distribution, and reproduction in any medium, provided the original work is properly cited.

\begin{abstract}
Nanocomposite magnetic polymer electrolytes based on poly(vinyl alcohol) (PVA) complexed with lithium hydroxide (LiOH) and containing magnetite $\left(\mathrm{Fe}_{3} \mathrm{O}_{4}\right)$ nanoparticles were prepared using an in situ method, in which the nanoparticles were grown in the host polymer electrolyte. Ion carriers were formed during nanoparticle growth from the previously added LiOH precursor. If a high concentration of $\mathrm{LiOH}$ was added, the remaining unreacted $\mathrm{LiOH}$ was distributed in the form of an amorphous complex around the $\mathrm{Fe}_{3} \mathrm{O}_{4}$ nanoparticles, thus preventing agglomeration of the nanoparticles by the host polymer. $\mathrm{By}$ addition of $\mathrm{Fe}_{3} \mathrm{O}_{4}$ the composite polymer electrolytes improved the ionic conductivity, resulting in a maximum conductivity of $1.81 \times 10^{-3} \mathrm{~S} \cdot \mathrm{cm}^{-1}$. The magnetic properties of the polymer electrolyte were investigated through magnetic susceptibility studies, and the material was predominantly ferromagnetic.
\end{abstract}

\section{Introduction}

The normal role of inorganic particle fillers in polymer electrolytes is to influence the recrystallization kinetics of the polymer chain and promote localized amorphous regions, thus enhancing cation transport. Examples of inorganic particles used in polymer composites include $\mathrm{SiO}_{2}, \mathrm{Al}_{2} \mathrm{O}_{3}$, $\mathrm{TiO}_{2}, \mathrm{CdO}$, and $\mathrm{ZnO}[1-9]$. Inorganic particles are also used to enhance the mechanical properties of polymer electrolytes [10]. Most authors agree that the role of nanoparticle fillers is very important and must be present in the host polymer for proper function.

Magnetic nanoparticles such as magnetite $\left(\mathrm{Fe}_{3} \mathrm{O}_{4}\right)$ have a unique response to magnetic fields and a saturation magnetization much lower than that of the corresponding bulk materials. The saturation magnetization decreases with particle size $[11,12]$. One interesting point is that dispersion of $\mathrm{Fe}_{3} \mathrm{O}_{4}$ nanoparticles in polymer electrolytes may also assist in ionic transport. We sought to produce a magnetic polymer electrolyte containing $\mathrm{Fe}_{3} \mathrm{O}_{4}$ nanoparticles as magnetic centers. This class of materials has considerable potential for producing devices that simultaneously interact with both electrical and magnetic fields, such as magnetic electrochemical cells and sensors.
The $\mathrm{Fe}_{3} \mathrm{O}_{4}$ nanoparticles were produced using a coprecipitation method. Two typical synthetic approaches are coprecipitation of partly oxidized $\mathrm{Fe}^{2+}$ to $\mathrm{Fe}^{3+}$ in oxidizing solutions and direct coprecipitation of $\mathrm{Fe}^{2+}$ and $\mathrm{Fe}^{3+}$ in alkaline media $[13,14]$. This approach ensures facile dispersion of the nanoparticles in the host polymer without requiring intensive mixing. Since the $\mathrm{LiOH}$ solution contained lithium ions, the insertion of lithium ion carriers in the composite occurred during growth of the $\mathrm{Fe}_{3} \mathrm{O}_{4}$ nanoparticles. Since the $\mathrm{Fe}_{3} \mathrm{O}_{4}$ displays magnetic behavior, we obtain a new class of polymer electrolytes known as nanocomposite magnetic polymer electrolytes.

\section{Experimental}

2.1. Materials. The poly(vinyl) alcohol (PVA, MW $22,000 \mathrm{~g} / \mathrm{mol}$ ) host polymer was obtained from Bratachem, Indonesia. Lithium hydroxide $(\mathrm{LiOH})$ was obtained from Kanto Chemical, Japan. The magnetite $\left(\mathrm{Fe}_{3} \mathrm{O}_{4}\right)$ nanoparticles were prepared from precursor solutions containing iron nitrate $\left(\mathrm{Fe}\left(\mathrm{NO}_{3}\right)_{3}\right)$ as a source of $\mathrm{Fe}^{3+}$ ion and iron sulfate $\left(\mathrm{FeSO}_{4}\right)$ as a source of $\mathrm{Fe}^{2+}$ ions, which was obtained from Merck, Germany. 
2.2. Preparation of the Charge Membranes. PVA.LiOH mixtures were prepared containing $0-10 \mathrm{wt} \%$. The PVA and $\mathrm{LiOH}$ were dissolved in separate solutions. The solutions were mixed at $50^{\circ} \mathrm{C}$ for $2 \mathrm{~h}$ and evaporated under ambient condition for 5 days to obtain a thin sheet of polymer electrolyte. The polymer composition exhibiting the highest electrical conductivity was used to prepare the magnetic material containing dispersed $\mathrm{Fe}_{3} \mathrm{O}_{4}$ nanoparticles. The nanoparticles were prepared using an in situ coprecipitation method in the host PVA.LiOH. Between volume fraction 0$0.35 \mathrm{v} \%$ of $\mathrm{Fe}_{3} \mathrm{O}_{4}$ nanoparticles were dispersed in the host polymer electrolyte.

2.3. Characterization. Structural studies were carried out on the PVA.LiOH and (PVA.LiOH): $\mathrm{Fe}_{3} \mathrm{O}_{4}$ membranes using $\mathrm{X}$-ray diffraction (XRD) analysis (Philips Analytical-Diffractometer PW1710, using $\mathrm{Cu}-\mathrm{K}_{\alpha}$ radiation). The sample was scanned in the $2 \theta$ ranging from $10^{\circ}$ to $80^{\circ}$ for $2 \mathrm{~s}$ in the step mode. Electrical conductivity measurements were obtained using electrochemical impedance spectroscopy (EIS) at frequencies from $20 \mathrm{~Hz}$ to $2 \mathrm{MHz}$ (Agient E4980A Precion LCR meter). The surface morphology of the polymer electrolyte membranes was examined using a scanning electron microscope (SEM JEOL JSM-6360LA). The magnetic properties were measured using a Bartington MS2B susceptibility meter.

\section{Results and Discussion}

Figure 1 is the complex membrane impedance spectrum (Nyquist Plot) of pure PVA and several PVA.LiOH mixtures. The squares represent experimental data and the curve is an approximation from the equivalent circuit used to determine the bulk resistance $\left(R_{b}\right)$. The ionic conductivity of polymer electrolytes was calculated using the relationship:

$$
\sigma=\frac{1}{R_{b}} \frac{\ell}{A}
$$

where $\ell$ is the thickness and $A$ is the cross-section of the membrane.

The room-temperature ionic conductivity of the membranes as a function of $\mathrm{LiOH}$ concentration is plotted in Fig-ure 2. The ionic conductivity increased with increasing $\mathrm{LiOH}$ concentration in the host polymer to a maximum at $9 \mathrm{wt} \%$.

The increase in ionic conductivity with $\mathrm{LiOH}$ concentration is due to an increase in the number of mobile charge carriers and a decrease in the crystallinity of the host polymer similar to that previously reported for other polymer electrolyte systems [15-17]. The decrease in ionic conductivity at concentrations greater than $9 \mathrm{wt} \%$ may be explained by the aggregation of ions. An excess of ions in the host polymer can result in ionic interactions with the polymer chains, leading to restriction of the segmental relaxation of the polymer chain (Figure 3).
In order to further improve the ionic conductivity, inorganic fillers were added to the host polymer. $\mathrm{Fe}_{3} \mathrm{O}_{4}$ nanoparticles were dispersed in situ in the host polymer electrolyte containing $9 \mathrm{wt} \% \mathrm{LiOH}$ using a coprecipitation technique:

$$
\begin{aligned}
& \mathrm{FeSO}_{4}+5 \mathrm{Fe}\left(\mathrm{NO}_{3}\right)_{3}+16 \mathrm{LiOH} \\
& \quad \longrightarrow 2 \mathrm{Fe}_{3} \mathrm{O}_{4}+15 \mathrm{LiNO}_{3}+\mathrm{LiSO}_{4}+8 \mathrm{H}_{2} \mathrm{O}
\end{aligned}
$$

The reaction produced black-colored particles indicating the formation of $\mathrm{Fe}_{3} \mathrm{O}_{4}$ nanoparticles in the polymer electrolyte matrix (Figure 4). Synthesis of $\mathrm{Fe}_{3} \mathrm{O}_{4}$ nanoparticles in a polymer electrolyte matrix results in smaller particles with excellent dispersion, while synthesis of $\mathrm{Fe}_{3} \mathrm{O}_{4}$ nanoparticles outside the polymer matrix results in formation of particle aggregates. Sensitivity to an external magnetic field was used as simple proof of the formation of magnetic nanoparticles, and the results were supported by XRD and magnetic measurements.

Dispersion of $\mathrm{Fe}_{3} \mathrm{O}_{4}$ nanoparticles in the host polymer enhanced the ionic conductivity. The nanoparticles assist ionic transport by increasing segmental mobility and interaction between $\mathrm{Li}^{+}$ions and the polymer chains. In addition, the presence of $\mathrm{Fe}_{3} \mathrm{O}_{4}$ nanoparticles in the polymer electrolyte alters the electrical potential distribution around the particle surface, which induces a space charge layer at the interface between the particles and the electrolyte. The typical room temperature complex impedance spectrum of the polymer electrolyte PVA.LiOH containing dispersed $\mathrm{Fe}_{3} \mathrm{O}_{4}$ nanoparticles exhibiting maximum conductivity is shown Figure 5. The conductivity of the prepared samples at room temperature is found to be $\sim 10^{-3} \mathrm{~S} \cdot \mathrm{cm}^{-1}$.

In order to explain the effect of $\mathrm{Fe}_{3} \mathrm{O}_{4}$ nanoparticles on ionic conductivity, we used the effective medium approximation (EMA) to calculate the effective ionic conductivity. The model was developed by considering that a polymer electrolyte is composed of amorphous and crystalline phases, as illustrated in Figure 6.

Carrier accumulation near the particle surfaces locally enhances the ionic conductivity due to the increased carrier concentration, leading to a high-conductivity region. In areas far from any nanoparticles, the carrier concentration is approximately equal to that in the pure electrolyte (when insulator particles are absent). These areas are known as mediumconductivity regions. When two particles make contact, the electrolyte medium between the particles is removed and ion transport does not occur. The conductivity of this region is reduced to nearly zero (approximately equal to that of insulator particles), and these are known as low-conductivity regions. The effective ionic conductivity satisfies the equation:

$$
\begin{gathered}
\left(\frac{v}{f}\right)^{2} \frac{\sigma_{l}-\sigma_{e}}{\sigma_{l}+(z / 2-1) \sigma_{e}}+\left(\frac{1-\nu}{f}\right)^{2} \frac{\sigma_{m}-\sigma_{e}}{\sigma_{m}+(z / 2-1) \sigma_{e}} \\
+2\left(\frac{v}{f}\right)\left(\frac{1-\nu}{f}\right) \frac{\sigma_{h}-\sigma_{e}}{\sigma_{h}+(z / 2-1) \sigma_{e}}=0
\end{gathered}
$$

in which $\nu, f, z, \sigma_{l}, \sigma_{m}$, and $\sigma_{h}$ are the volume fraction of the particle, the packing fraction, the coordination number, and the conductivity of the low, medium, and high conductivity regions. 


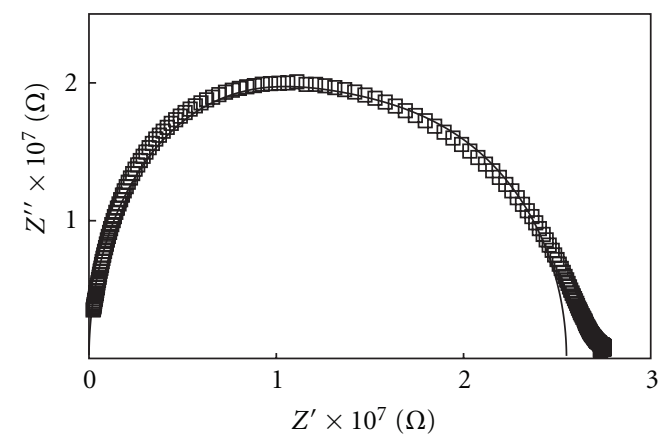

(a)

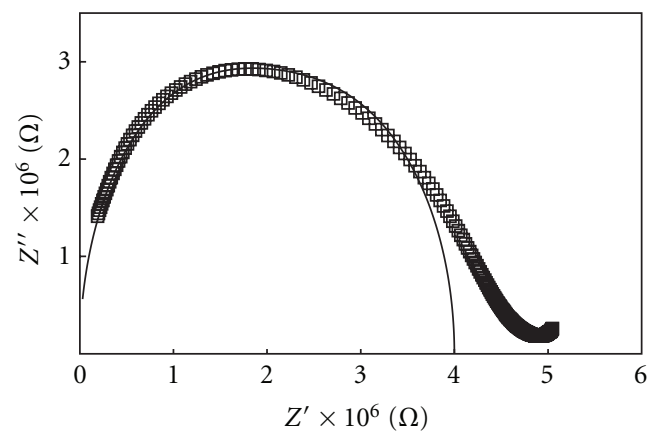

(c)

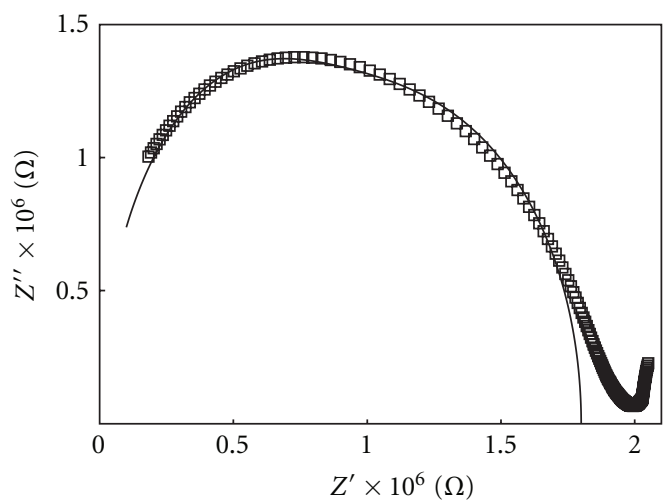

(e)

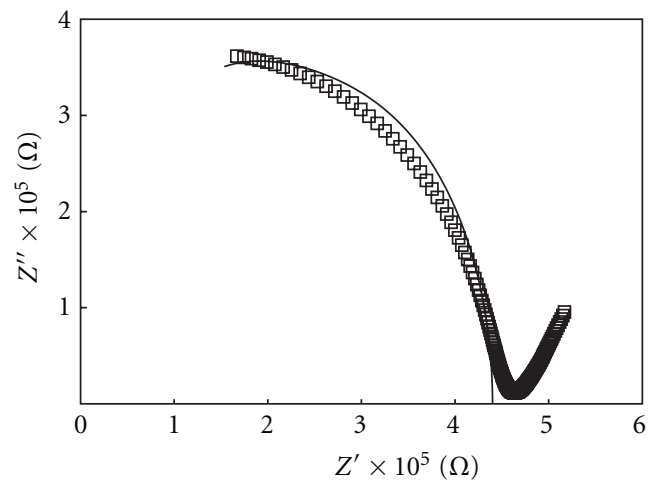

(g)

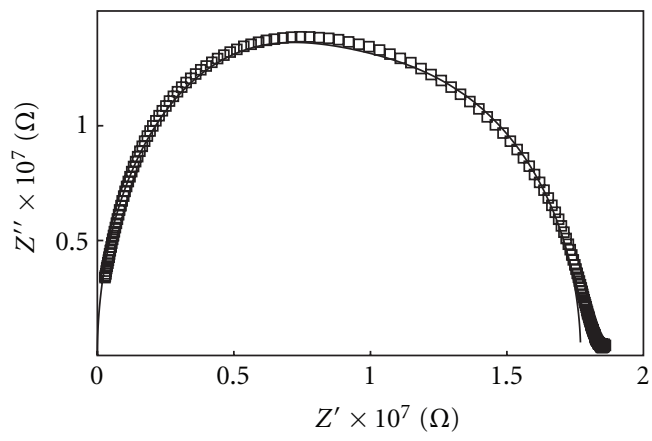

(b)

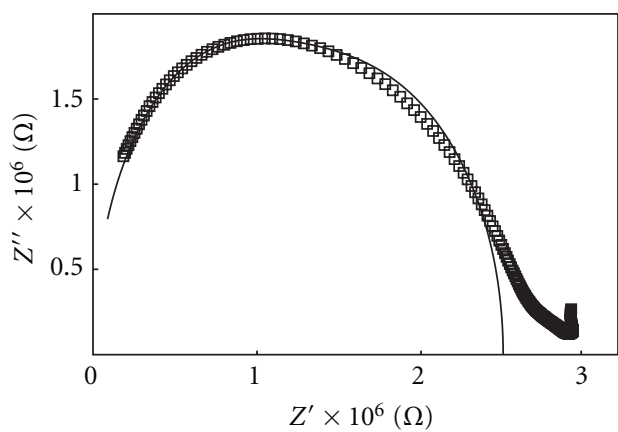

(d)

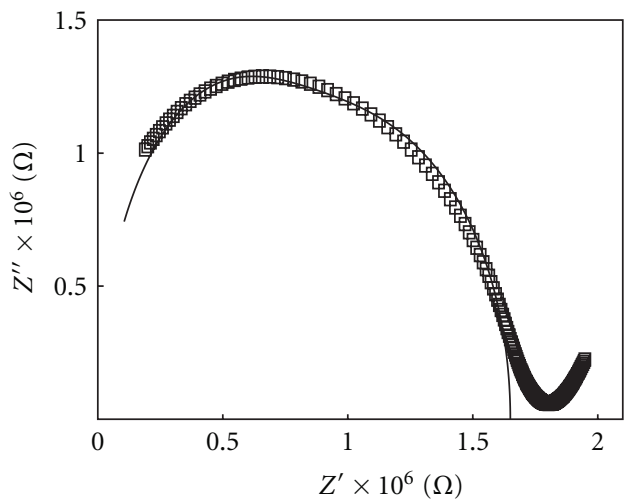

(f)

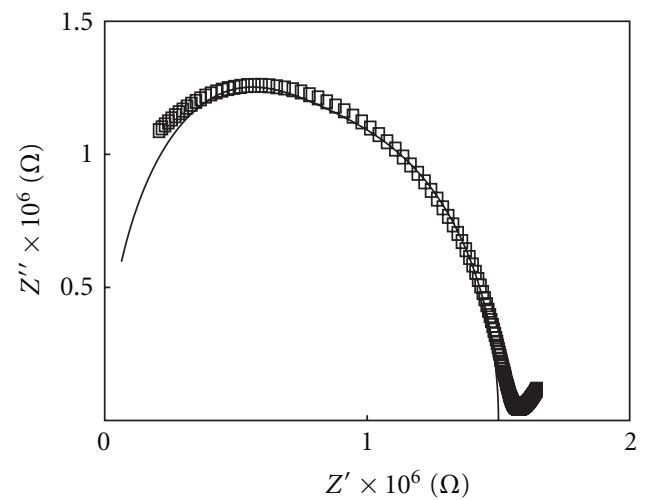

(h)

FIgURE 1: Impedance spectrum and fitting curve for PVA.LiOH complex membrane polymer electrolyte at room temperature (a) 0 wt $\%$ $\mathrm{LiOH},(\mathrm{b}) 1 \mathrm{wt} \%$, (c) $3 \mathrm{wt} \%$, (d) $5 \mathrm{wt} \%$, (e) $7 \mathrm{wt} \%$, (f) $8 \mathrm{wt} \%$, (g) $9 \mathrm{wt} \%$, and (h) $10 \mathrm{wt} \%$. 


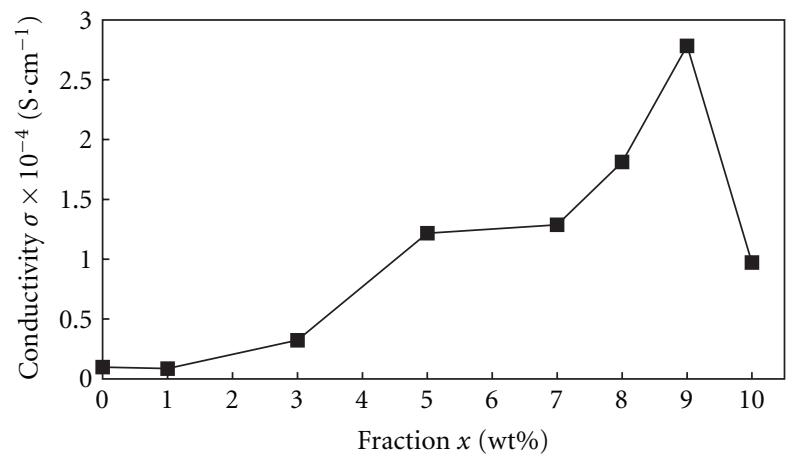

FIGURE 2: Ionic conductivity of PVA.LiOH polymer electrolyte as function of LiOH weight fraction. Measurements were performed at room temperature.

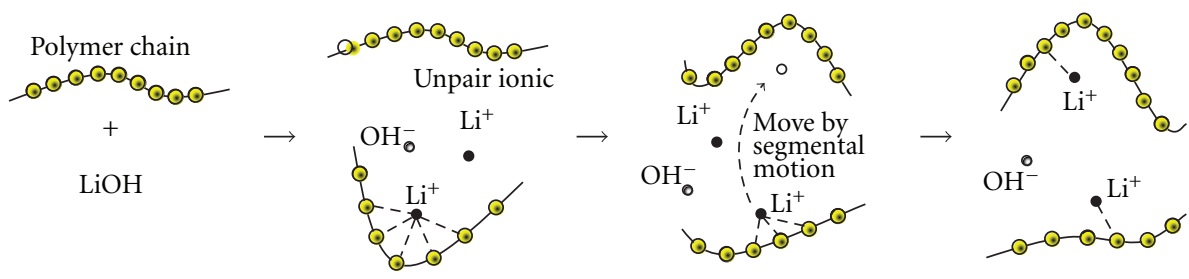

FIGURE 3: Schematic of ionic transport by relaxation segmental motion of polymer chains.

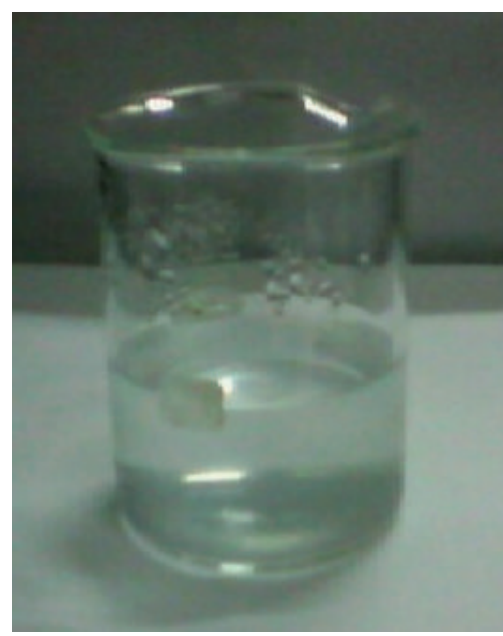

(a)

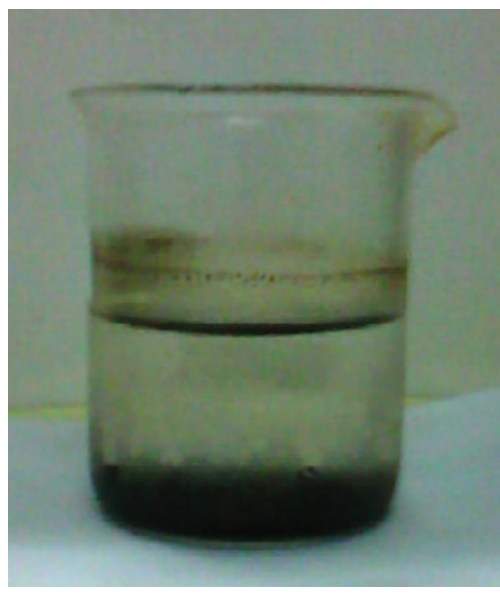

(c)

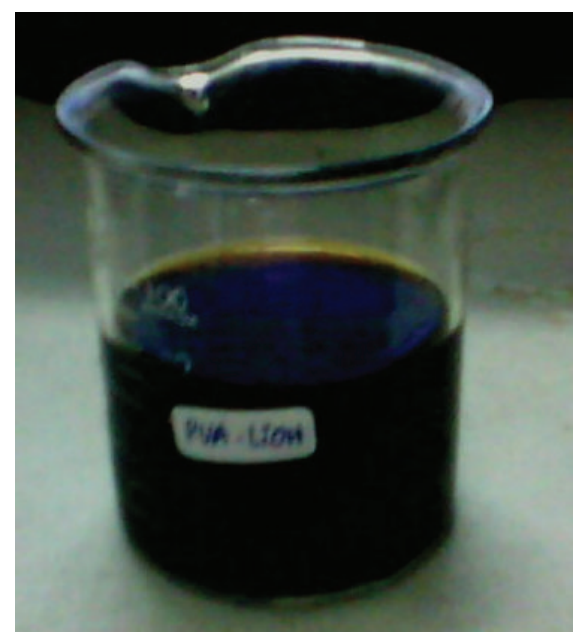

(b)

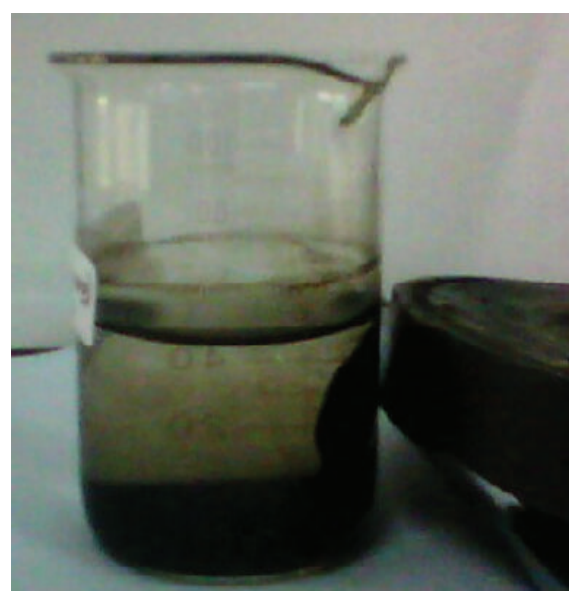

(d)

Figure 4: Solution of (a) PVA.LiOH polymer electrolyte, (b) polymer electrolyte containing dispersed $\mathrm{Fe}_{3} \mathrm{O}_{4}$ particles, (c) $\mathrm{Fe}_{3} \mathrm{O}_{4}$ particles in absence of polymer matrix, and (d) Response of $\mathrm{Fe}_{3} \mathrm{O}_{4}$ particles to external magnetic field. 


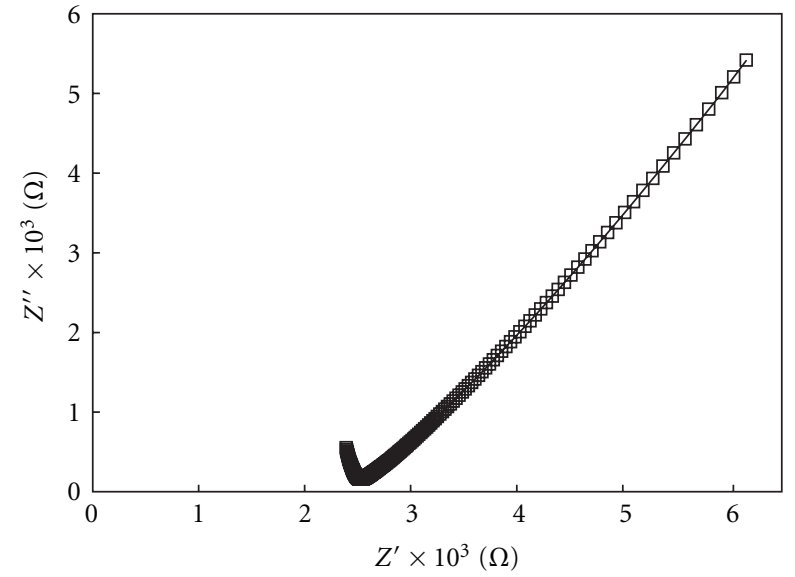

Figure 5: Impedance spectrum of PVA.LiOH containing dispersed $\mathrm{Fe}_{3} \mathrm{O}_{4}$.

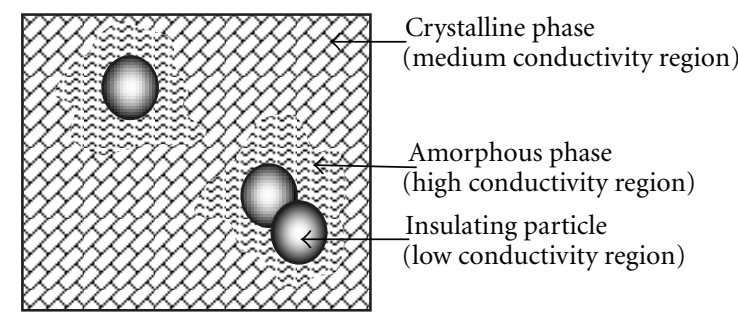

FIGURE 6: Illustration of particle arrangement in composite polymer electrolyte. Amorphous phases having high conductivity are created around the particles.

Figure 7 is a graph of the ionic conductivity of the composite polymer electrolyte as a function of $\mathrm{Fe}_{3} \mathrm{O}_{4}$ nanoparticle volume fraction. The solid line is a plot of (3) assuming simple cubic packing of filler particles in which $z=6$ and $f=\pi / 6$. The other parameters in the equation were $\sigma_{l}=$ $10^{-6} \mathrm{~S} \cdot \mathrm{cm}^{-1}, \sigma_{m}=2.2 \times 10^{-4} \mathrm{~S} \cdot \mathrm{cm}^{-1}$, and $\sigma_{h}=40 \sigma_{m}$. There was consistent agreement between the predicted and experimental conductivity. The maximum conductivity occurred with an $\mathrm{Fe}_{3} \mathrm{O}_{4}$ volume fraction of approximately $\approx 0.22$.

The ionic conductivity results are supported by the Xray diffraction patterns observed in PVA complexed with various amounts of $\mathrm{LiOH}$ and $\mathrm{Fe}_{3} \mathrm{O}_{4}$ (Figure 8). Pure PVA in the form of a powder or membrane exhibits a peak at $20^{\circ}$ characteristic of an orthorhombic lattice, indicating the presence of a semicrystalline phase [15-17]. The intensity of the XRD peaks decreased with increasing $\mathrm{LiOH}$ concentration, indicating a reduction in crystallinity in the host polymer. Similar behavior was observed in membranes containing $\mathrm{Fe}_{3} \mathrm{O}_{4}$ nanoparticles.

Figure 9 contains SEM images depicting the morphology of PVA, PVA.LiOH membranes with and without $\mathrm{Fe}_{3} \mathrm{O}_{4}$ nanoparticles. The morphology of the PVA membrane was uniform, and the surface roughness increased with increasing $\mathrm{LiOH}$ concentration.

However, the morphology of the membrane containing $\mathrm{Fe}_{3} \mathrm{O}_{4}$ nanoparticles was fragmented. The fragments may

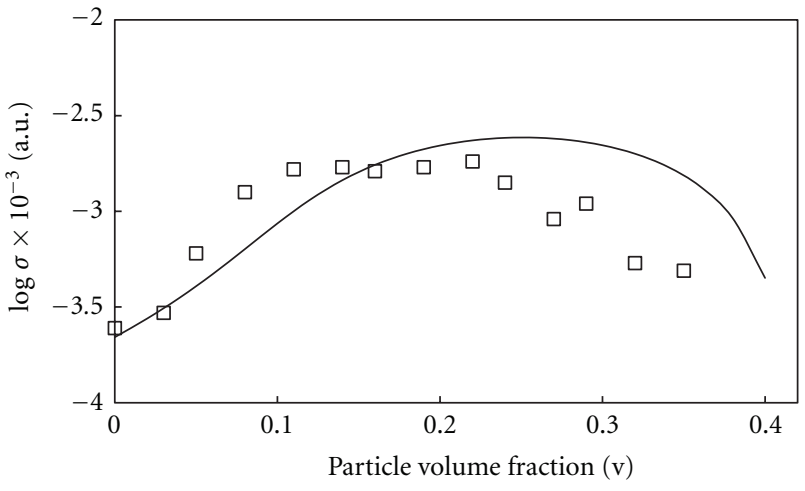

FIGURE 7: Effect of particle volume fraction on electrical conductivity of magnetic composites. Symbols represent experimental data and curve was obtained using (3) with the following parameters: $z=6$ and $f=\pi / 6, \sigma_{l}=10^{-6} \mathrm{~S} \cdot \mathrm{cm}^{-1}, \sigma_{m}=2.2 \times 10^{-4} \mathrm{~S} \cdot \mathrm{cm}^{-1}$ and $\sigma_{h}=40 \sigma_{m}$.

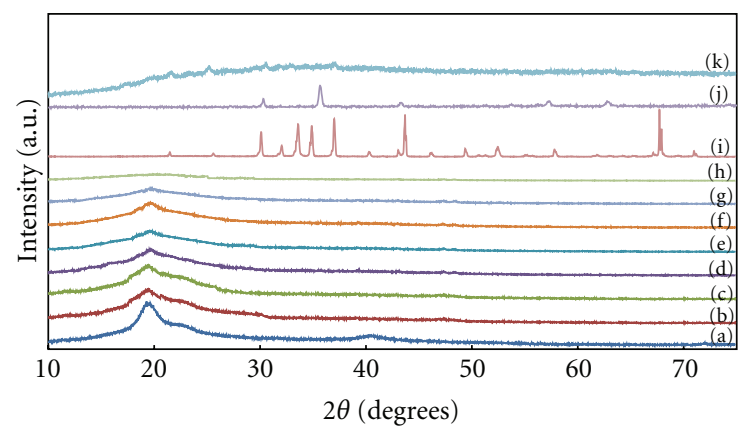

Figure 8: XRD patterns for (a) PVA powder, (b) PVA membrane, (c) $1 \mathrm{wt} \%$, PVA.LiOH. (d) $3 \mathrm{wt} \%$ PVA.LiOH, (e) $5 \mathrm{wt} \%$ PVA.LiOH, (f) $7 \mathrm{wt} \%$ PVA.LiOH, (g) $9 \mathrm{wt} \%$ PVA.LiOH, (h) $10 \mathrm{wt} \%$ PVA.LiOH, (i) $\mathrm{LiOH}$ powder, (j) $\mathrm{Fe}_{3} \mathrm{O}_{4}$ powder, and (k) composite membrane containing $9 \mathrm{wt} \%$ dispersed $\mathrm{Fe}_{3} \mathrm{O}_{4}$ nanoparticles.

have been formed as the $\mathrm{Fe}_{3} \mathrm{O}_{4}$ nanoparticles filled the empty spaces between polymer chains. This is supported by the results of EDS analysis indicating that the host polymer composition (C (71.02\%), O (11.53\%), and $\mathrm{FeO}(12.06 \%)$ ) was retained in the nanoparticle-containing membranes. $\mathrm{Fe}_{3} \mathrm{O}_{4}$ particles synthesized in the absence of a polymer matrix possess an irregular morphology.

Magnetic susceptibility $(\chi)$ is a simple technique for observing the presence of magnetic particles. It is sensitive enough to detect very low concentrations of magnetic materials. PVA.LiOH membranes not containing $\mathrm{Fe}_{3} \mathrm{O}_{4}$ nanoparticles were weakly diamagnetic, with susceptibilities of $\chi=$ $-63.14 \times 10^{-8} \mathrm{~m}^{3} \cdot \mathrm{kg}^{-1}$. The susceptibility increased with increasing $\mathrm{Fe}_{3} \mathrm{O}_{4}$ content, although the increase was slower at higher concentrations (Table 1).

The intensity of the magnetic susceptibility was a function of the $\mathrm{Fe}_{3} \mathrm{O}_{4}$ nanoparticle concentration. However, the relationship was nonlinear, possibly due to an inhomogeneous dispersion of $\mathrm{Fe}_{3} \mathrm{O}_{4}$ nanoparticles in the polymer electrolyte. 


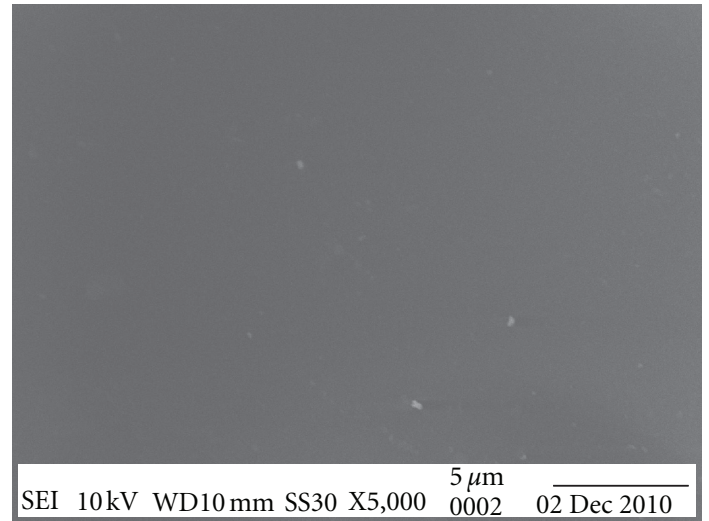

(a)

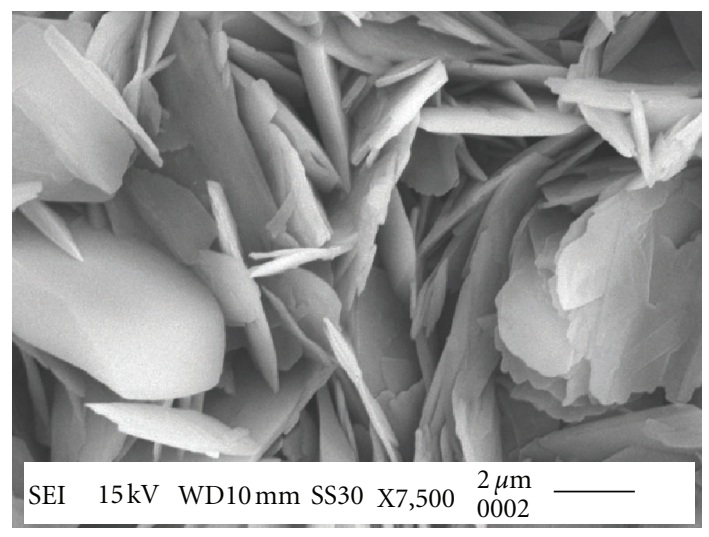

(c)

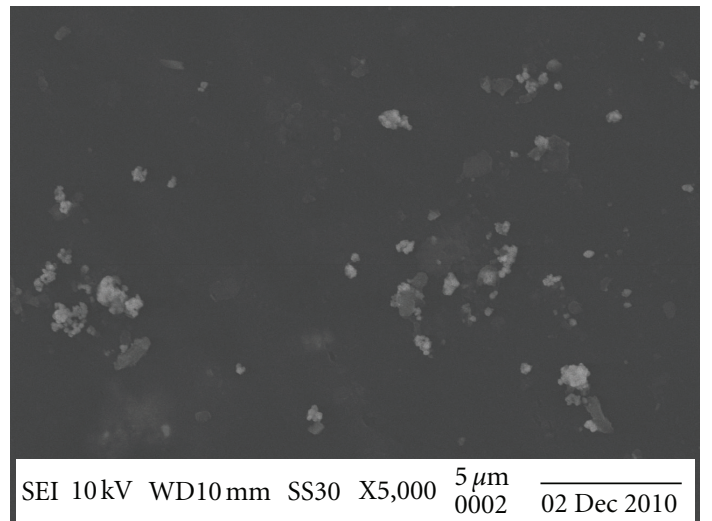

(b)

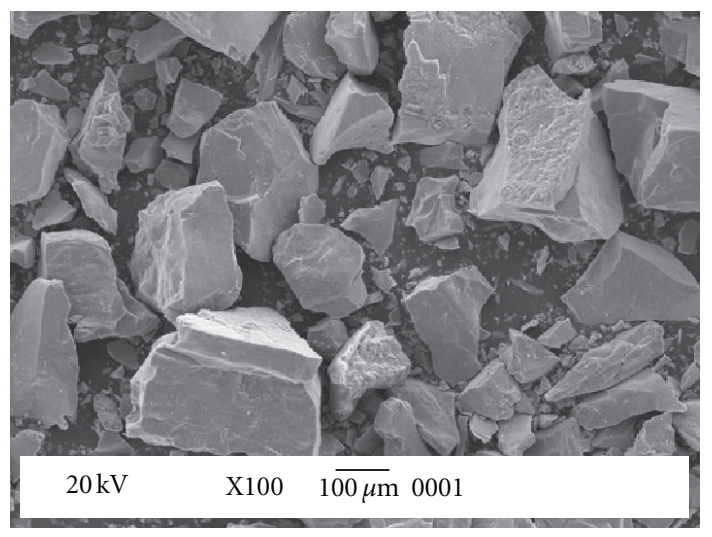

(d)

Figure 9: SEM images of (a) PVA membrane, (b) $9 \mathrm{wt} \%$ PVA.LiOH membrane, (c) 9 wt\% PVA.LiOH containing $\mathrm{Fe}_{3} \mathrm{O}_{4}$ nanoparticles, and (d) $\mathrm{Fe}_{3} \mathrm{O}_{4}$ particles synthesized in absence of polymer matrix.

TABLE 1: Magnetic susceptibility of composite polymer electrolyte as a function of $\mathrm{Fe}_{3} \mathrm{O}_{4}$ nanoparticle content.

\begin{tabular}{lc}
\hline $\begin{array}{l}\text { Volume fraction } \\
\mathrm{Fe}_{3} \mathrm{O}_{4}\end{array}$ & $\begin{array}{c}\chi_{m} \times 10^{-8} \\
\left(\mathrm{~m}^{3} \cdot \mathrm{kg}^{-1}\right)\end{array}$ \\
\hline 0.00 & -63.14 \\
0.03 & 36 \\
0.05 & 112 \\
0.08 & 67 \\
0.11 & 468 \\
0.14 & 737 \\
0.16 & 227 \\
0.19 & 1159 \\
0.22 & 575 \\
0.24 & 3300 \\
0.27 & 642 \\
0.29 & 1158 \\
0.32 & 4134 \\
0.35 & 1404 \\
\hline
\end{tabular}

\section{Conclusion}

A new nanocomposite magnetic polymer electrolyte was synthesized by dispersing magnetite $\left(\mathrm{Fe}_{3} \mathrm{O}_{4}\right)$ nanoparticles in membrane composed of PVA.LiOH complex. The $\mathrm{Fe}_{3} \mathrm{O}_{4}$ nanoparticles assisted ionic transport through an increase in segment mobility and interaction between $\mathrm{Li}^{+}$ions and the polymer chains. The results suggest that nanocomposite magnetic polymer electrolytes may be suitable for use in magnetic-electrochemical devices.

\section{Acknowledgment}

This work was supported by Doctoral Research Grant 2010/ 2011, Bandung Institute of Technology, Indonesia.

\section{References}

[1] K. Pandey, M. M. Dwivedi, M. Tripathi, M. Singh, and S. L. Agrawal, "Structural, thermal and ion transport studies on nanocomposite polymer electrolyte $\left(\mathrm{PEO}+\mathrm{SiO}_{2}\right): \mathrm{NH}_{4} \mathrm{SCN}$ system," Ionics, vol. 14, no. 6, pp. 515-523, 2008.

[2] P. C. Chun-yue, Z. Qian, F. Qing, G. Jin-huan, and Z. Youman, "Preparation and properties of $\mathrm{PEO} / \mathrm{LiClO}_{4} / \mathrm{KH}_{560}-\mathrm{SiO}_{2}$ composite polymer electrolyte by sol-gel composite-in-situ method," Journal of Central South University of Technology, vol. 15, pp. 438-442, 2008.

[3] S. L. Agrawal, M. Singh, M. Tripathi, M. M. Dwivedi, and K. Pandey, "Dielectric relaxation studies on $\left[\mathrm{PEO}-\mathrm{SiO}_{2}\right]$ : 
$\mathrm{NH}_{4} \mathrm{SCN}$ nanocomposite polymer electrolyte films," Journal of Materials Science, vol. 44, no. 22, pp. 6060-6068, 2009.

[4] S. A. Suthanthiraraj and D. J. Sheeba, "Structural investigation on PEO-based polymer electrolytes dispersed with $\mathrm{Al}_{2} \mathrm{O}_{3}$ nanoparticles," Ionics, vol. 13, no. 6, pp. 447-450, 2007.

[5] M. M. Rao, J. S. Lio, W. S. Li, Y. H. Liao, Y. Liang, and L. Z. Zhao, "Polyethylene-supported poly(acrylonitrile-co-methyl methacrylate)/nano-Al2O3 microporous composite polymer electrolyte for lithium ion battery," Journal of Solid State Electrochemistry, vol. 14, no. 2, pp. 255-260, 2010.

[6] S. P. Low, A. Ahmad, and Y. A. Rahman, "Effect of ethylene carbonate plasticizer and $\mathrm{TiO} 2$ nanoparticles on $49 \%$ poly(methyl methacrylate) grafted natural rubber-based polymer electrolyte," Ionics, vol. 16, no. 9, pp. 821-826, 2010.

[7] G. Rajasudha, H. Shankar, P. Thangadurai, N. Boukos, V. Narayanan, and A. Stephen, "Preparation and characterization of polyindole- $\mathrm{ZnO}$ composite polymer electrolyte with $\mathrm{LiClO}_{4}$," Ionics, vol. 16, no. 9, pp. 839-848, 2010.

[8] M. Y. A. Rahman, A. Ahmad, and S. A. Wahab, "Electrical properties of a solid polymeric electrolyte of PVC-ZnO$\mathrm{LiClO}_{4}$," Ionics, vol. 15, no. 2, pp. 221-225, 2009.

[9] A. Karmakar and A. Ghosh, "Improvement of electrical conductivity of poly ethylene oxide (PEO)-LiI polymer electrolytes is necessary for their use in solid," Journal of Nanoparticle Research, vol. 13, pp. 2989-2996, 2011.

[10] S. Ramesh and L. C. Wen, "Investigation on the effects of addition of $\mathrm{SiO}_{2}$ nanoparticles on ionic conductivity, FTIR, and

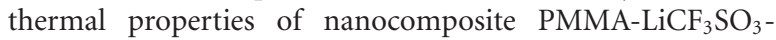
$\mathrm{SiO}_{2}$," Ionics, vol. 16, no. 3, pp. 255-262, 2010.

[11] M. Abdullah, I. W. Lenggoro, K. Okuyama, and F. G. Shi, "In situ synthesis of polymer nanocomposite electrolytes emitting a high luminescence with a tunable wavelength," Journal of Physical Chemistry B, vol. 107, no. 9, pp. 1957-1961, 2003.

[12] D. Maity and D. C. Agrawal, "Synthesis of iron oxide nanoparticles under oxidizing environment and their stabilization in aqueous and non-aqueous media," Journal of Magnetism and Magnetic Materials, vol. 308, no. 1, pp. 46-55, 2007.

[13] J. Philip, P. D. Shima, and B. Raj, "Enhancement of thermal conductivity in magnetite based nanofluid due to chainlike structures," Applied Physics Letters, vol. 91, no. 20, Article ID 203108, 3 pages, 2007.

[14] I. Nedkov, T. Merodiiska, L. Slavov, R. E. Vandenberghe, Y. Kusano, and J. Takada, "Surface oxidation, size and shape of nano-sized magnetite obtained by co-precipitation," Journal of Magnetism and Magnetic Materials, vol. 300, no. 2, pp. 358$367,2006$.

[15] P. B. Bhargav, V. M. Mohan, A. K. Sharma, and V. V. R. N. Rao, "Investigations on electrical properties of (PVA:NaF) polymer electrolytes for electrochemical cell applications," Current Applied Physics, vol. 9, no. 1, pp. 165-171, 2009.

[16] P. B. Bhargav, V. M. Mohan, A. K. Sharma, and V. V. R. N. Rao, "Structural and electrical properties of pure and $\mathrm{NaBr}$ doped poly (vinyl alcohol) (PVA) polymer electrolyte films for solid state battery applications," Ionics, vol. 13, no. 6, pp. 441-446, 2007.

[17] P. B. Bhargav, V. M. Mohan, A. K. Sharma, and V. V. R. N. Rao, "Structural, electrical and optical characterization of pure and doped poly (vinyl alcohol) (PVA) polymer electrolyte films," International Journal of Polymeric Materials, vol. 56, no. 6, pp. 579-591, 2007. 

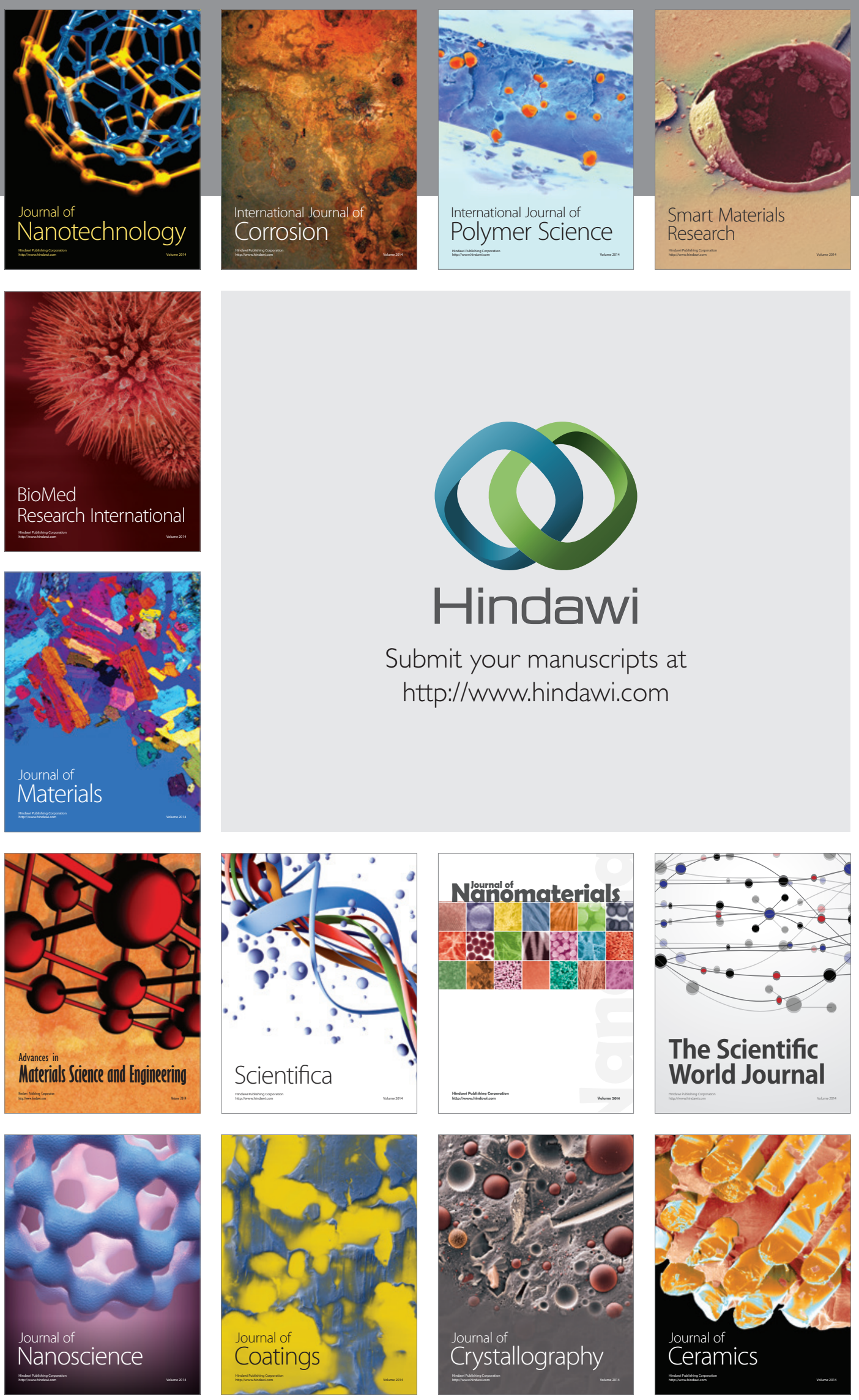

The Scientific World Journal

Submit your manuscripts at

http://www.hindawi.com

\section{World Journal}

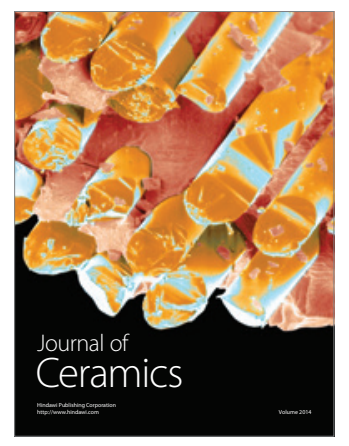

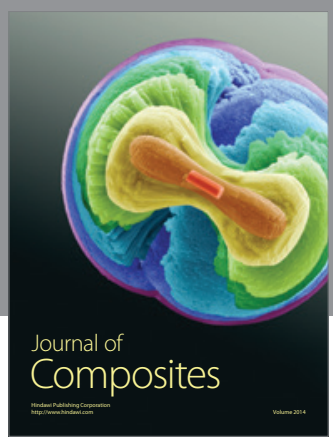
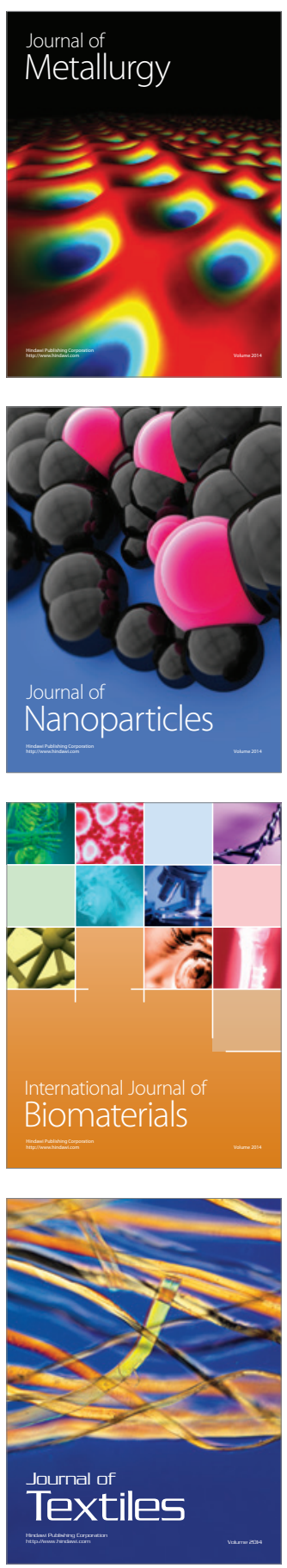